\title{
Seasonal expressions of SPAG11A and androgen receptor in the epididymis of the wild ground squirrels (Spermophilus dauricus Brandt)
}

\author{
Wenyang Yu, Ziwen Zhang, Pei Liu, Xiaoying Yang, Haolin Zhang, Zhengrong Yuan, Yingying Han, \\ Qiang Weng
}

Laboratory of Animal Physiology, College of Biological Sciences and Technology, Beijing Forestry University, Beijing, China

Sperm-associated antigen 11A (SPAG11A), a protein expressed exclusively in the epididymis, plays a vital and special role in regulating mammalian sperm maturation. The aim of this study was to investigate the seasonal expressions of SPAG11A and androgen receptor (AR) in the epididymis of the wild ground squirrels (Spermophilus dauricus Brandt). Morphologically, the results showed that epididymis length and weight in the breeding season were significantly higher than those of the non-breeding season. Histologically, the results revealed that enlarged lumen diameters, thickened epithelium and abundant sperm in the breeding season while reduced lumen diameters and epithelium with no sperm in the non-breeding season. SPAG11A was intensely expressed in cytoplasm and nucleus of epithelial cells and smooth muscle cells in the breeding season, and weaker staining in the non-breeding season. In the lumen of epididymis, SPAG11A immunostaining in the sperm of the epididymal corpus and cauda was higher than those in the caput during the breeding season. The immunostaining of AR was only presented in nucleus of smooth muscle cells and epithelial cells in the epididymis from the breeding season rather than the non-breeding season. The results of real-time quantitative PCR also showed that the mRNA levels of SPAG11A and AR in the epididymis during the breeding season were significantly higher than those of the non-breeding season. In addition, the circulating testosterone, follicle-stimulating hormone and luteinizing hormone levels in the squirrels were higher in the breeding season compared with those in the non-breeding season. Taken together, these results implied that SPAG11A might be involved in regulating seasonal changes in epididymal functions of the wild ground squirrels.

Key words: Androgen receptor; epididymis; sperm-associated antigen 11A; testosterone; wild ground squirrel.

Correspondence: Yingying Han, Laboratory of Animal Physiology, College of Biological Sciences and Biotechnology, Beijing Forestry University, Beijing 100083, China. Tel.: +86 10-6233-8682.

E-mail: thinkinghyy@bjfu.edu.cn

Contributions: WY, ZZ, XY, QW, experiments performing, data analysis, manuscript drafting; WY, PL, samples collection assistance, experiments performing; HZ, ZY, YH, QW study design and supervision, manuscript revision. All authors read and approved the final version and agreed to be accountable for all aspects of the work.

Conflict of interest: The authors declare that they have no competing interests, and all authors confirm accuracy.

Ethics approval and consent to participate: All procedures involving animals were carried out in accordance with the Policy on the Care and Use of Animals by the Ethical Committee, Beijing Forestry University and approved by the Department of Agriculture of Hebei Province, China (JNZF11/2007). 


\section{Introduction}

The mammalian epididymis is a highly convoluted and important organ during male mammalian reproduction, providing a critical microenvironment for sperm maturation, protection, storage, and transportation. ${ }^{1}$ As a connecting between the testis and vas deferens, the epididymis is generally divided into three segments, including caput epididymis (head), corpus epididymis (body), and cauda epididymis (tail). ${ }^{2}$ In rodents, an additional segment called initial segment (IS) is located between the efferent ducts and the caput epididymis. ${ }^{3}$ All these segments possess distinct patterns of gene expression and cell types that important for the different steps of sperm maturation under physiological condition. ${ }^{4}$ There are 5 major cell types in the epididymis epithelium, including principal, clear, narrow, basal, and halo cells. Among them, the clear and narrow cells differ not only from each other but also from principal and basal cells in their structure and relative distribution. ${ }^{5}$ They also express different proteins within the distinct epididymal regions, implying their various regulatory functions in male reproduction. ${ }^{6}$ Moreover, the epididymal epithelial cells also help to establish and maintain a unique intraluminal environment for epididymal sperm transport by forming a blood-epididymis barrier through tight junctions. ${ }^{7}$ At the same time, the epididymis is proved to be an androgen-dependent organ, thus the presence of androgens is required for many aspects of epididymal function, such as the process of sperm maturation and storage. ${ }^{8}$

$\beta$-defensins are host defense peptides that are cationic and have a canonical series of cysteines held in a classic antiparallel $\beta$-sheet structure stabilized by three intramolecular disulphide bonds. ${ }^{9,10}$ Various $\beta$-defensin genes have been found in mammals (52 in mice, 43 in rats, and 43 in humans), and they form a total of 4-5 inline gene clusters. ${ }^{11}$ In addition to its antibacterial and immuneregulating functions, $\beta$-defensins also play a key role in the maturation of male reproductive functions. ${ }^{12}$ Previous study found that these proteins have an inclination of region- and cell-specific expression in the epithelium of the postnatal epididymis, ${ }^{13}$ and their secretion into the luminal microenvironment and binding to spermatozoa when they transport along the epididymis, suggesting that they were involved in male reproductive function. ${ }^{14}$ SPAG11A is a member of the $\beta$-defensin protein family exclusively expressed in the epididymis..$^{15}$ As a secreted protein in the male accessory sex gland, SPAG11A has been shown to play essential roles in sperm maturation and fertility in different species, such us rats, mice and humans. ${ }^{16}$ Some studies have clarified that SPAG11A was associated with androgen receptor binding sites in their promoter or intronic regions, indicating its direct regulation of androgen receptor (AR). ${ }^{13}$ However, as a SPAG11A isoforms, SPAG11B/C exhibited an androgen-independent expression pattern, ${ }^{17}$ the SPAG11E gene upstream sequence contains binding sites for androgen receptor , NF- $\kappa \mathrm{B}$, nuclear factor-1, E-twenty-six and activator protein $2,{ }^{18}$ but no studies indicated that SPAG11D was regulated by androgen. These proteins all have an important role in epididymal innate immunity, but in the male reproduction, only have some evidence show that SPAG11A/C and SPAG11E may participate in reproducing in rodents, most research on SPAG11B/D has focused on primates.

The Spermophilus dauricus Brandt, named wild ground squirrel is a typical long-day seasonal breeding animal. ${ }^{19}$ It usually hibernates from late September to late March of the following year and breeds once a year. When the temperature rises in spring, the wild ground squirrel wakes from hibernation and begins to estrus mating, generally from April to May each year. After 28 days of pregnancy, the wild ground squirrels can produce 6 to 8 offsprings per year. ${ }^{20,21}$ We have already published many studies that demonstrated seasonal changes of gonadal functions in the wild ground squirrel, ${ }^{19,22}$ which is a completely natural and highly useful wild mammal animal model for exploring the important roles of reproductive hormones and local growth factors in the seasonal regulation of reproductive system. Our previous results have found the expressions of P450arom, ERs (ER alpha and ER beta), PDGF-A in the epididymis of the wild ground squirrels, which suggested that androgen, estrogen, PDGF-A could regulate epididymal functions. $^{23,24}$ To better understand the seasonal changes in the epididymis of the wild ground squirrels, the present study investigated the expressions of SPAG11A and AR during the breeding and nonbreeding seasons to clarify the relationship between $\beta$-defensin and the epididymal functions of the wild ground squirrels.

\section{Materials and Methods}

\section{Animals}

The wild male ground squirrels that were thought to be adults based on their body weights (general standard range of body weight for adult squirrel: $242-412 \mathrm{~g}$ ) were captured by box traps in April $28^{\text {th }}$ (the breeding season, $n=10$ ) and June $18^{\text {th }}$ (the nonbreeding season, $\mathrm{n}=10$ ) of 2019 in Heibei province, China. All procedures involving animals were carried out in accordance with the Policy on the Care and Use of Animals by the Ethical Committee, Beijing Forestry University and approved by the Department of Agriculture of Hebei Province, China (JNZF11/2007). An overdose of pentobarbital (BioDee Co., Beijing, China) was applied afterwards for euthanasia. Epididymal tissues were excised quickly after necropsy. On necropsy, the epididymis was excised, weighed, measured and tissues were fixed in $4 \%$ paraformaldehyde in 0.05 M PBS ( $\mathrm{pH}$ 7.4) for histological and immunohistochemical observations, and the other epididymal tissues were immediately frozen in liquid nitrogen and stored at $-80^{\circ} \mathrm{C}$ until used for RNA isolation.

\section{Antibodies}

The primary antibodies used in the present study included rabbit polyclonal anti-AR (sc-816, Santa Cruz Biotechnology, Santa Cruz, CA, USA) and rabbit polyclonal anti-SPAG11A (bs-17617R, Beijing Biosynthesis Biotechnology Co. Ltd, Beijing, China), The dilution ranges of AR and SPAG11A antibodies for immunohistochemistry were all 1:500. The specificity of AR antibodies have been described in our previous studies in the wild ground squirrels. ${ }^{23}$ The immunohistochemistry kits with the secondary antibody of goat anti-rabbit was applied corresponding with the primary antisera.

\section{Histology}

The epididymal samples (the breeding season, $n=8$; the nonbreeding season, $n=8$ ) were dehydrated by a certain concentration of ethanol and embedded in paraffin wax. Serial sections $(5 \mu \mathrm{m})$ were dried on glass slides coated with poly-L-lysine (SigmaAldrich, St. Louis, MO, USA). Sections were stained with hematoxylin-eosin (HE) for general histological observations. All pictures were captured by a digital camera (EOS450D, Canon, Japan) attached to a light microscope (BX51, Olympus, Japan) under a 200x magnification. Cell populations of caput, corpus and cauda epididymis were counted from HE staining serial sections $(n=8)$ of each wild ground squirrel individuals. Three epididymal tubules of each HE staining were chosen randomly to count total cell numbers within the tubules. The results were summed and averaged to indicate the total cell number of each segment of epididymis from different seasons. 


\section{Immunohistochemistry}

Briefly, the serial sections of the epididymis tissues (the breeding season, $\mathrm{n}=5$; the non-breeding season, $\mathrm{n}=5$ ) were deparaffined and the antigen retrieval were performed via autoclave for $10 \mathrm{~min}$ at $121^{\circ} \mathrm{C}$ followed by the treatment with $0.3 \% \mathrm{H}_{2} \mathrm{O}_{2}$ in methanol for $30 \mathrm{~min}$. Those sections were blocked with $10 \%$ normal goat serum and then incubated with primary polyclonal antibodies in 1:500 dilution against SPAG11A (bs-17617R, Beijing Biosynthesis Biotechnology Co. Ltd, Beijing, China) and AR (sc816, Santa Cruz Biotechnology, Santa Cruz, CA, USA), for $12 \mathrm{~h}$ under $4^{\circ} \mathrm{C}$. The control sections were treated with normal rabbit IgG (DE0602, Biodee Biotechnology) at 1:2000 dilutions instead of the primary antibody. The sections were then incubated with a secondary antibody, goat anti-rabbit IgG conjugated with biotin and peroxidase with avidin, using rabbit ExtrAvidin Peroxidase staining Kit (Sigma Chemical Co), followed by visualizing with $20 \mathrm{mg}$ 3,3'-diaminobenzidine (Wako, Tokyo, Japan) solution in
$100 \mathrm{ml}$ of $0.05 \mathrm{M}$ Tris- $\mathrm{HCl}$ buffer, $\mathrm{pH} 7.6$, plus $17 \mu \mathrm{L} \mathrm{H}_{2} \mathrm{O}_{2}$. The immunostained slides were examined using a photomicroscope (BX51, Olympus, Tokyo, Japan).

\section{Total RNA isolation and cDNA synthesis}

Total RNA was isolated from epididymis tissues of the wide ground squirrels (the breeding season, $\mathrm{n}=8$; the non-breeding season, $\mathrm{n}=8$ ) using Trizol Reagent (Invitrogen, Carlsbad, CA, USA). Approximately $0.1 \mathrm{~g}$ of epididymis tissues were thawed and immediately homogenized in $1 \mathrm{~mL}$ of Trizol Reagent. The homogenate was incubated for $5 \mathrm{~min}$ at room temperature to allow the complete dissociation of nucleoprotein complexes. After the addition of 0.2 $\mathrm{mL}$ of chloroform, the mixture was vigorously shaken for $15 \mathrm{~s}$ at room temperature and centrifuged at $12,000 \mathrm{~g}$ for $15 \mathrm{~min}$ at $4{ }^{\circ} \mathrm{C}$. The aqueous phase was then transferred to a fresh tube and an equal volume of isopropanol was added. Then the sample was kept for $10 \mathrm{~min}$ at room temperature. RNA was precipitated by centrifugation at
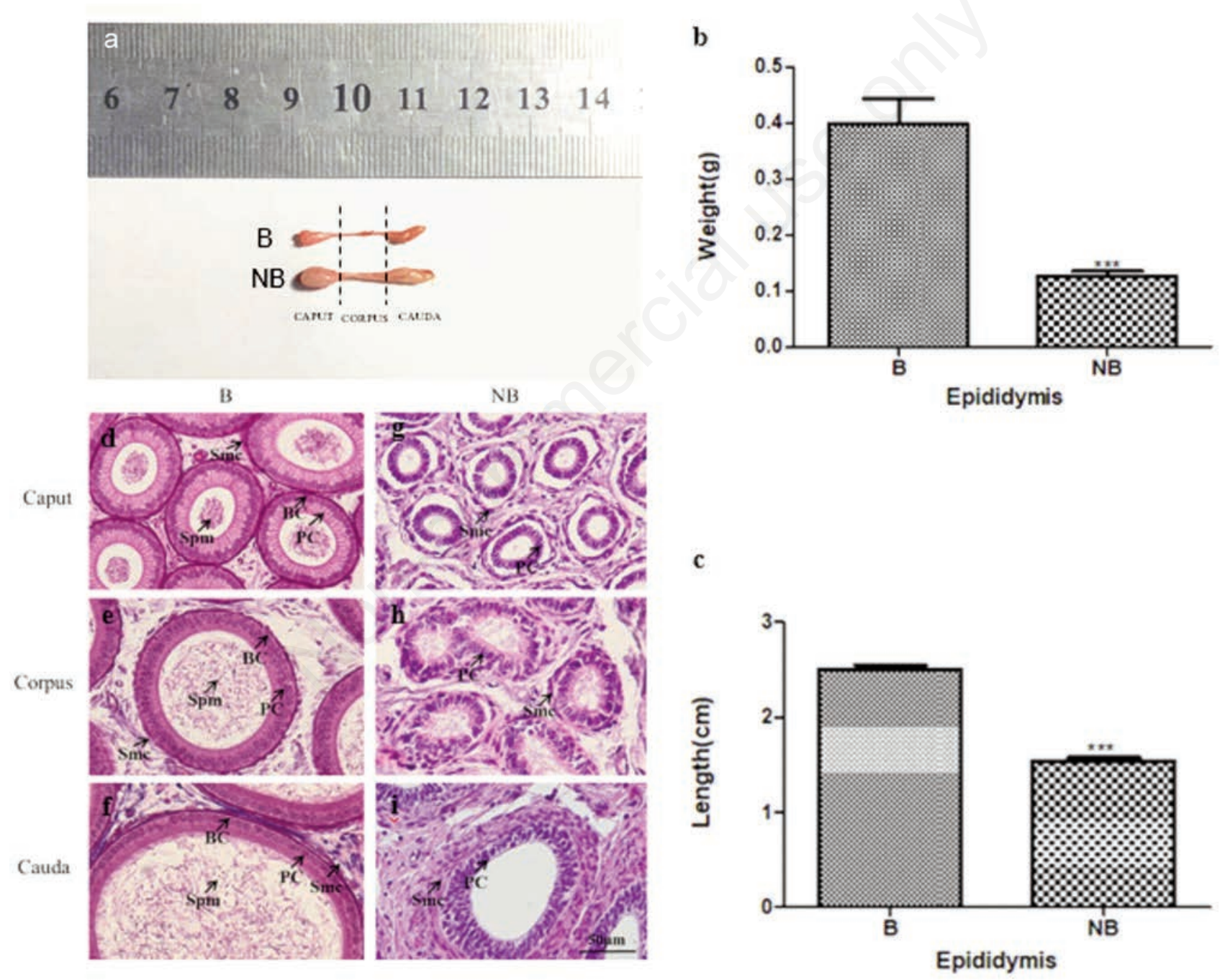

Figure 1. Seasonal change of epididymal morphology and histology in the breeding season and non-breeding season. a) Epididymis excised from the male wild ground squirrels during the breeding season and the non-breeding season: the dotted line indicated the boundaries of the epididymis tissue slice. $b)$ Average weights of epididymis $(n=10)$ during the breeding and non-breeding seasons. $c)$ Average length of epididymis $(n=10)$ during the breeding and non-breeding seasons. $d, e, f)$ Histological observations of the caput, corpus, and cauda epididymis during the breeding season $(n=5) . g, h, i)$ Histological observations of the caput, corpus, and cauda epididymis during the non-breeding season $(n=5)$. Spm, spermatozoa; PC, principal cell; SMC, smooth muscle cell; BC, basal cell; scale bar: $50 \mu \mathrm{m}$. B, the breeding season; NB, the non-breeding season. Data are shown as the mean \pm SEM. ${ }^{* * * P<0.001}$. 
$12,000 \mathrm{~g}$ for $10 \mathrm{~min}$ at $4^{\circ} \mathrm{C}$. The RNA pellet was washed twice with $70 \%$ ethanol and dissolved in $50 \mu \mathrm{L}$ of diethylprocarbonate-treated water. The integrity of RNA was tested by gel electrophoresis and its concentration was measured with spectrophotometer.

\section{Quantitative real-time PCR}

The cDNA was stored at $-20^{\circ} \mathrm{C}$. The cDNA fragment used for quantitative real-time PCR was amplified by primers $A R$-F: 5'TGGGACCTTGGATGGAGAAC-3' and R: 5'-CTCCGTAGTGACAGCCAGAA-3'; SPAG11A-F:5'-ACAGAGAGCGAGCCGTAAAA-3' and R: 5'-AGGCACACGGTGTTTCTGAT-3'; The annealing temperature used for all primers was $60^{\circ} \mathrm{C}$. The PCR reactions were carried out in a $10 \mu \mathrm{L}$ volume using FastStart Essential DNA Green Master (Roche Molecular System Inc.,
Basel, Switzerland). The PCR conditions were performed in ABI PRISM 7500 Fast Real-Time System (Applied Biosystems, Foster City, CA, USA) as described below: $10 \mathrm{~min}$ at $95^{\circ} \mathrm{C}$, followed by 40 cycles of $30 \mathrm{~s}$ at $95^{\circ} \mathrm{C}, 30 \mathrm{~s}$ at $60^{\circ} \mathrm{C}$ and $30 \mathrm{~s}$ at $72^{\circ} \mathrm{C}$. The melting curves were also performed to test the homogeneity of the PCR products by increasing the temperature progressively to $95^{\circ} \mathrm{C}$, then decreasing it to $65^{\circ} \mathrm{C}$ for $60 \mathrm{~s}$ and increasing it again to $95^{\circ} \mathrm{C}$. The target and reference genes had the similar PCR efficiency. Negative control reactions in the absence of reverse transcriptase were performed to test for genomic DNA contamination. All samples were run in triplicate, including a negative control and the intra-assay variation was less than $10 \%$. The expression level of each target mRNA relative to Actb mRNA was determined using the $2^{-\Delta \Delta C t}$ method. a
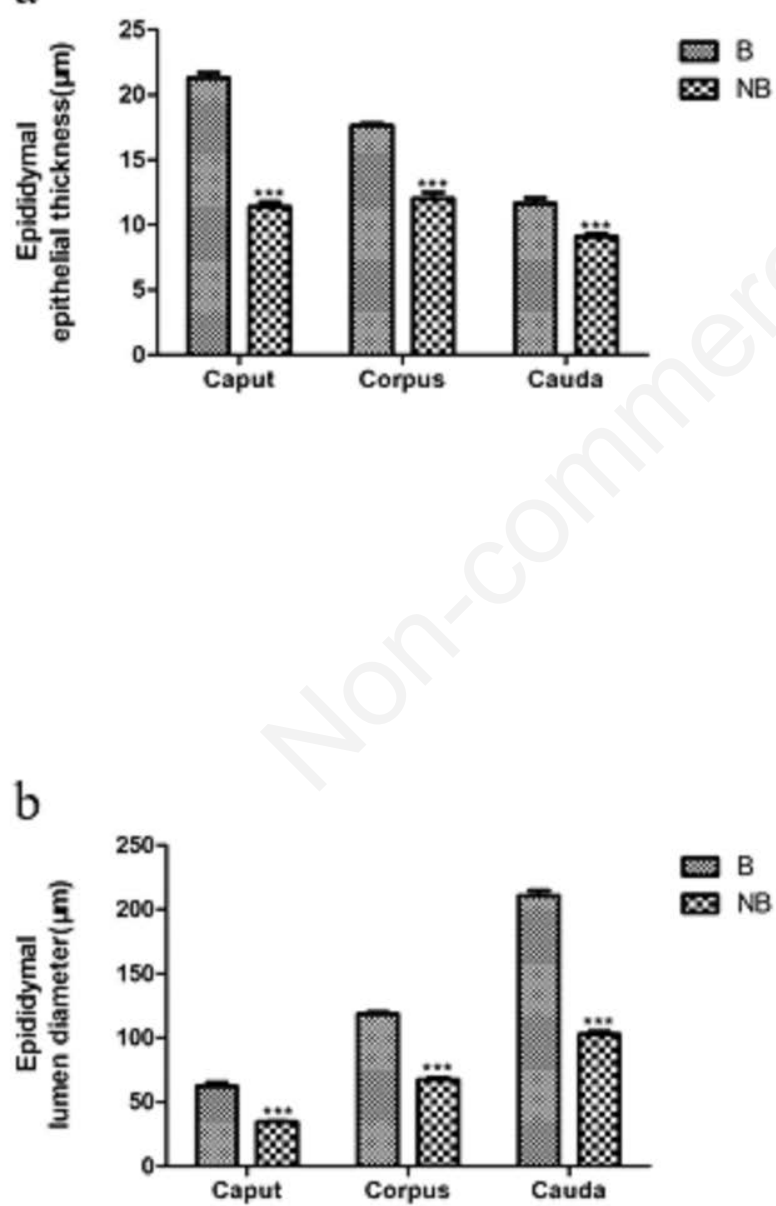

$B$

$\otimes N B$
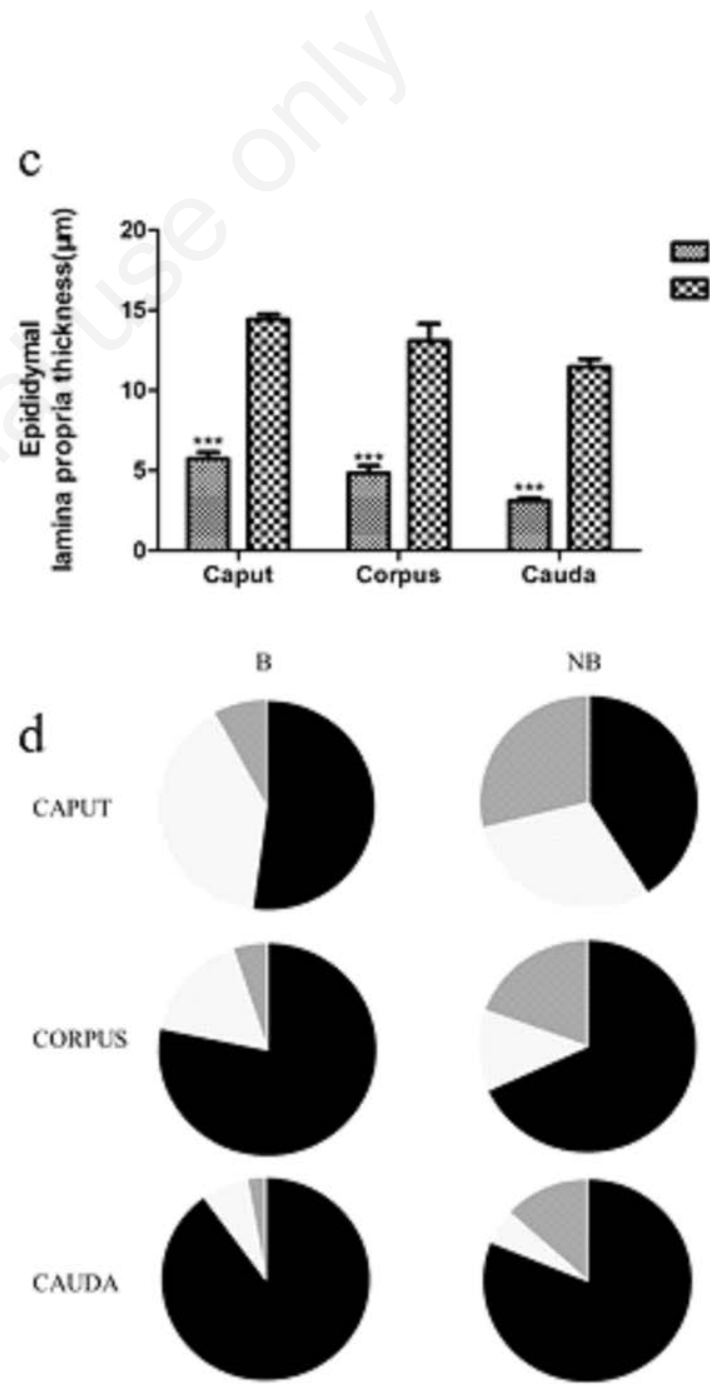

- Lumina Epithelium = lamina propria

Figure 2. Compositional changes in the histology of the epididymis during the different seasons. a,b,c) Comparison results of the lumen diameters, epithelial thickness, and lamina propria thicknesses of the caput, corpus and cauda epididymis during the breeding ( $n=8$ ) and non-breeding $(n=8)$ seasons. $d)$ The proportions of the different functional compartments (lumen, epithelial and lamina propria) within the caput, corpus and cauda epididymis during the breeding $(n=8)$ and non-breeding $(n=8)$ seasons. $B$, the breeding season; NB, the non-breeding season. Data are shown as the mean \pm SEM. ${ }^{* * *} \mathbf{P}<0.001$. 


\section{Hormone measurement}

The blood concentrations of luteinizing hormone ( $\mathrm{LH})$, follicle-stimulating hormone (FSH) and testosterone (T) were analysed by the enzyme linked immunosorbent assay (ELISA) using the corresponding ELISA Kits (Kit CSB-E12654r for LH, Kit CSBE06869r for FSH and Kit CSB-E05100r for T, Cusabio Biotech Co., Ltd., Wuhan, China). Samples preparation was performed following the user manual. Blood samples were centrifuged for 15 min at $1,000 \mathrm{~g}$ at $4^{\circ} \mathrm{C}$, and then the supernatant of plasma was collected and assayed immediately. The validation of ELISA Kit for the wild ground squirrels were checked by examining the parallelism between the standard curve and series diluted sample curve. The intra- and inter-assay coefficient of variation were $<15 \%$, in the assay using LH, FSH and T, respectively.

\section{Statistical analysis}

Statistical comparisons were made with the Student's $t$-test and one-way ANOVA followed by using Graphpad prism software (ver. 5.0, GraphPad Software, Inc., San Diego, CA, USA). A value of $\mathrm{P}<0.05$ was considered indication of statistical significance.

\section{Results}

\section{Morphology and histology of epididymis}

The observed morphology and histology of the epididymis during the breeding and non-breeding seasons are showed in Figure 1. The epididymal average weighs and lengths in the breeding season were significantly higher than those of the non-breeding season. In the breeding season, there were thicker epididymal epithelium and larger epididymal lumen with abundant mature sperms. However, in the non-breeding season, epididymal lumen became smaller with no sperm and thinner epididymal epithelium compared to those in the breeding season. Regardless of the breeding period or non-breeding period seasons, the values of lumen and epithelium were decreased in the order of caput, corpus and cauda. Meanwhile, there were marker difference of lamina propria in these two periods. In the breeding season, the thickness of epididymal lamina propria was significantly decreased. Furthermore, the proportions of the different functional compartments (lumen, epithelium, and lamina propria) within the epididymis had indicated distinct variances between the caput, corpus, and cauda epididymis during the breeding and nonbreeding seasons, as showed in Figure 2.

\section{Caput}
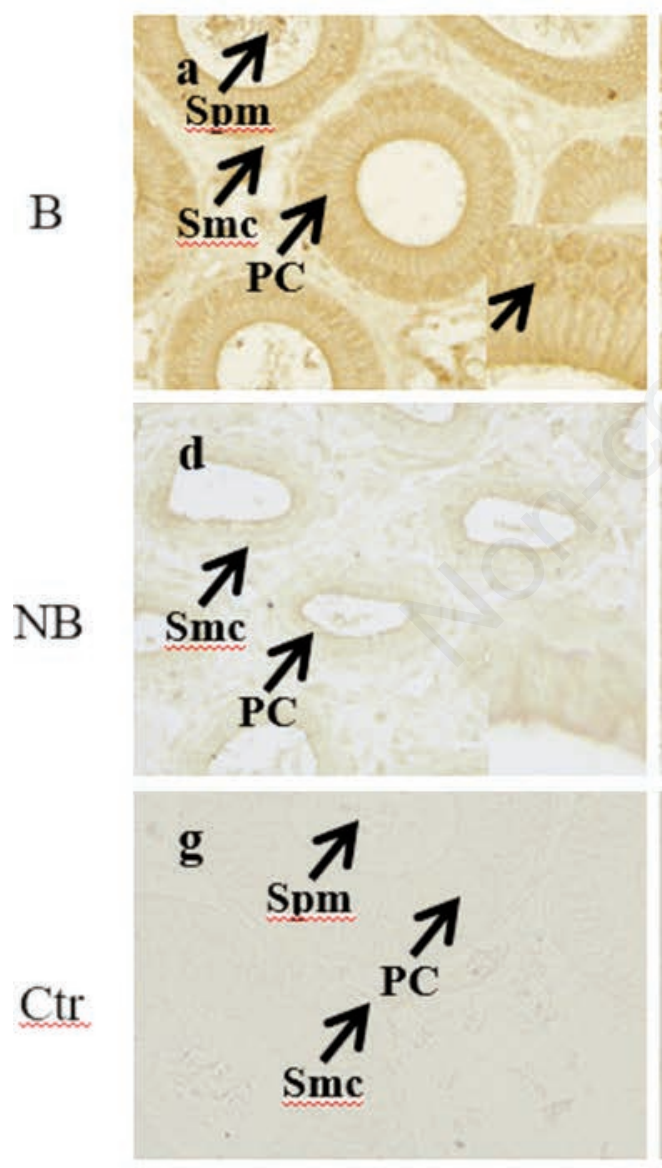

Corpus
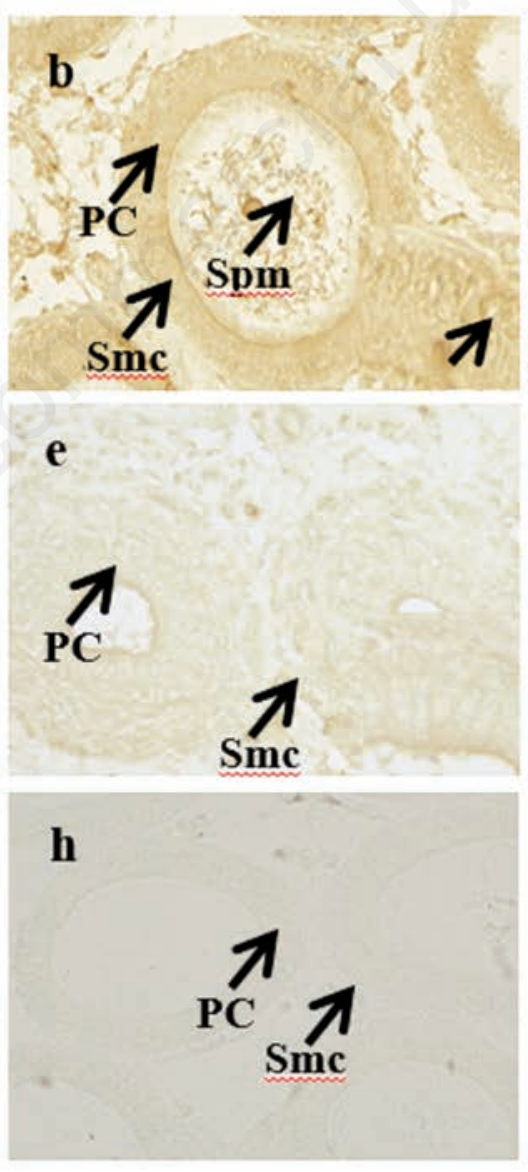

Cauda
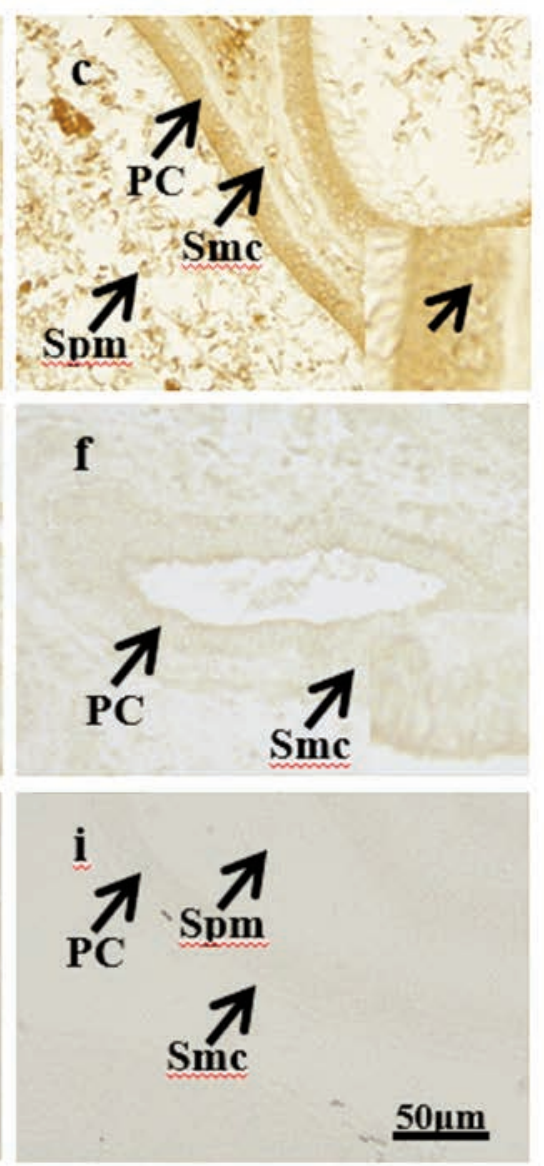

Figure 3. Immunohistochemical results of SPAG11A in the epididymis of the wild ground squirrels during the breeding and non-breeding seasons. a-c) Immunolocalization of the SPAG11A in the breeding season was presented in first row. d-f) Immunolocalization of the SPAG11A in the breeding season was presented in second row. g-i) The last row represents negative control of two seasons. Spm, spermatozoa; PC, principal cell; SMC, smooth muscle cell; B, the breeding season; NB, the non-breeding season. 


\section{Immunochemical localizations of SPAG11A and AR in} the epididymis

Immunochemical staining of SPAG11A and AR were performed in epididymis of the breeding season and non-breeding season (Figures 3 and 4). SPAG11A was localized in the nucleus and cytoplasm of principal and smooth muscle cells with stronger staining in the breeding season than those of the non-breeding season (Figure 3 a-f), and we also observed that the immunostaining of sperm SPAG11A in the lumen of corpus and cauda was higher than those in the caput epididymis (Figure $3 \mathrm{a}-\mathrm{c}$ ). Similar to the staining of SPAG11A, during the breeding season, the most extensive immunostaining of AR was also present in the nucleus of epithelial and smooth muscle cells (Figure 4 a-c). However, the staining signals of SPAG11A and AR decreased in the non-breeding season (Figure $3 \mathrm{~d}$-f; Figure $4 \mathrm{~d}-\mathrm{f}$ ). In the negative control, no signal was observed.

The expressions of SPAG11A and AR mRNA in the epididymis of the wild ground squirrels

SPAG11A and AR mRNA levels were also detected in the epi- didymis of the wild ground squirrels during the breeding and nonbreeding seasons (Figure 5). The mRNA levels of the SPAG11A in the caput epididymis were observed to be significantly higher during breeding season than those during the non-breeding season, but there were no significant differences in the expression of SPAG11A between the corpus and cauda epididymis $(\mathrm{P}<0.05)$. The expression levels of AR gene in the caput, corpus and cauda epididymis were significantly higher during the breeding season than those during the non-breeding season $(\mathrm{P}<0.05)$.

\section{The circulating FSH, LH and T concentrations}

The levels of FSH, LH and T were measured in the plasm of the male wild ground squirrels during both the breeding season and non-breeding season. FSH levels had decreased from $1.98 \pm 0.06$ $\mathrm{ng} / \mathrm{mL}$ during the breeding season to $0.18 \pm 0.01 \mathrm{ng} / \mathrm{mL}$ during the non-breeding season (Figure 6a). LH levels had also decreased from $3.18 \pm 0.26 \mathrm{ng} / \mathrm{mL}$ during the breeding season to $0.22 \pm 0.02$ $\mathrm{ng} / \mathrm{mL}$ during the non-breeding season (Figure $6 \mathrm{~b}$ ). Moreover, similar results were observed in the levels of $\mathrm{T}$, it has declined from $7.3 \pm 0.19 \mathrm{ng} / \mathrm{mL}$ to $1.9 \pm 0.04 \mathrm{ng} / \mathrm{mL}$ (Figure $6 \mathrm{c}$ ).
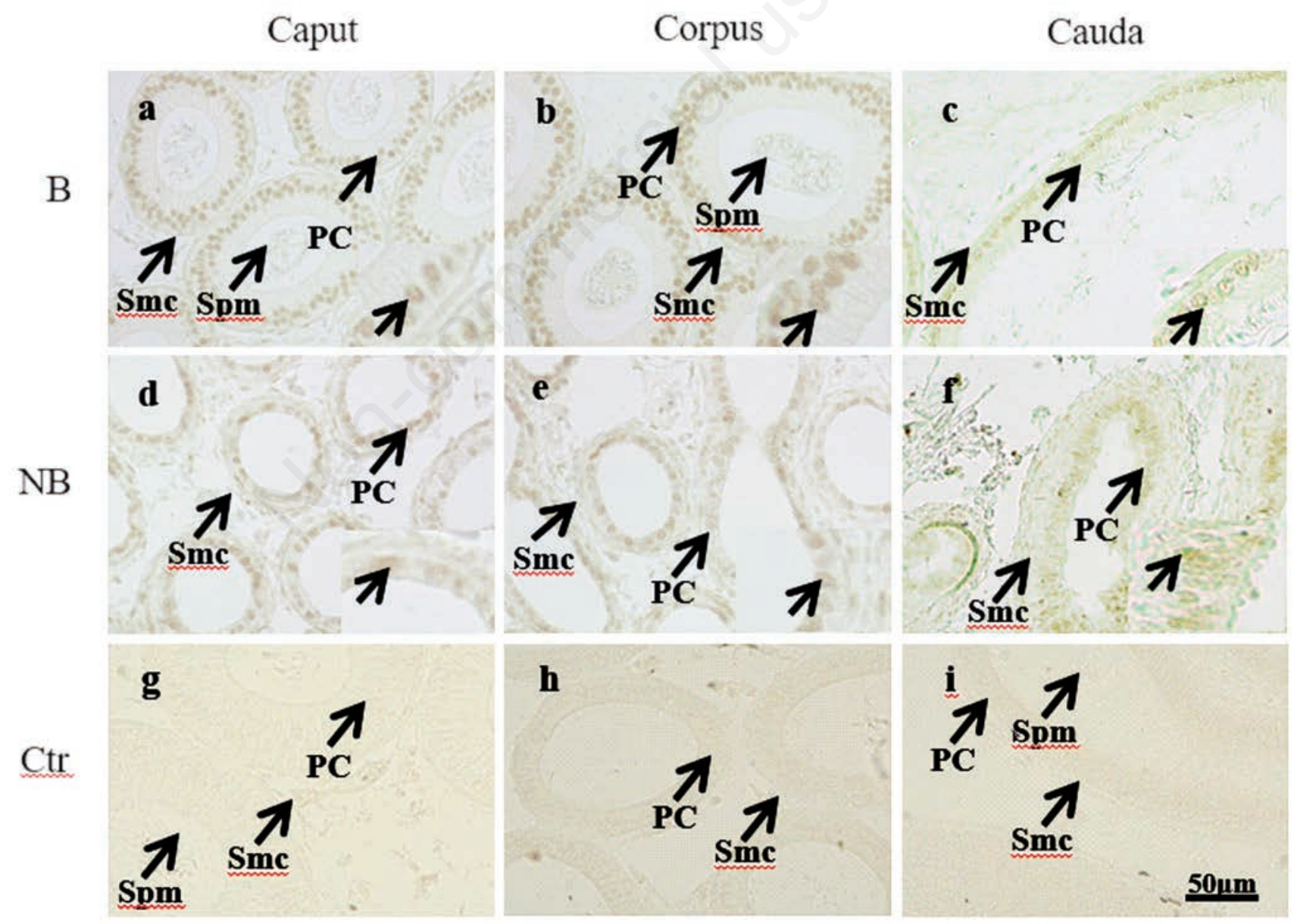

Figure 4. Immunohistochemical results of AR in the epididymis of the wild ground squirrels during the breeding and non-breeding seasons. a-c) Immunolocalization of AR in the breeding season was presented in first row. $d-f$ ) Immunolocalization of AR in the breeding season was presented in second row. g-i) The last row represents negative control of two seasons. Spm, spermatozoa; PC, principal cell; SMC, smooth muscle cell; B, the breeding season; NB, the non-breeding season. 


\section{Discussion}

In this study, we firstly revealed the immunolocalization and seasonal expression patterns of SPAG11A and AR in the epididymis of the wild ground squirrels during the breeding and non-breeding seasons. The present results showed that the expressional patterns of SPAG11A and AR in the epididymis were along with the seasonal changes of epididymal functions, and there was a parallel change between the concentrations of $\mathrm{T}$ and the expression levels of SPAG11A. Seasonal changes in the expression of SPAG11A and AR in the epididymis in the breeding and non-breeding seasons suggested that SPAG11A might be involved in creating a microenvironment suitable for sperm maturation and fertility. Animals make use of changes in photoperiod to adapt their physiology to the forthcoming breeding season..$^{25}$ Therefore, seasonal change of morphological and histological characteristic of epididymis were observed in seasonal breeding mammals. ${ }^{24,26,27}$ The present results illustrated that the epididymis significantly expanded with abundant sperms during the breeding season. It was similar with other seasonal breeding mammals including Neotropical bat, ${ }^{28}$ dromedary camel, ${ }^{29}$ sand rat, ${ }^{30}$ which showed larger epididymis during their reproductive period. The seasonal variation of epididymal mass shown in the present study was in agreement with the previous reports in this species, ${ }^{26}$ indicating that the epididymal mass was greatest in the breeding season. Furthermore, we found that the thickness of the epididymal lamina propria significantly decreased during the breeding season when compared with that in the non-breeding season. These findings were observed to be similar with the results of previous studies about hamsters subjected to artificial short photoperiods and vizcacha undergoing short-day natural photoperiod changes, ${ }^{31,32}$ suggesting that enlarged epithelial height and declined lamina propria thickness in the epididymis might potentially contribute to maintaining spermato-

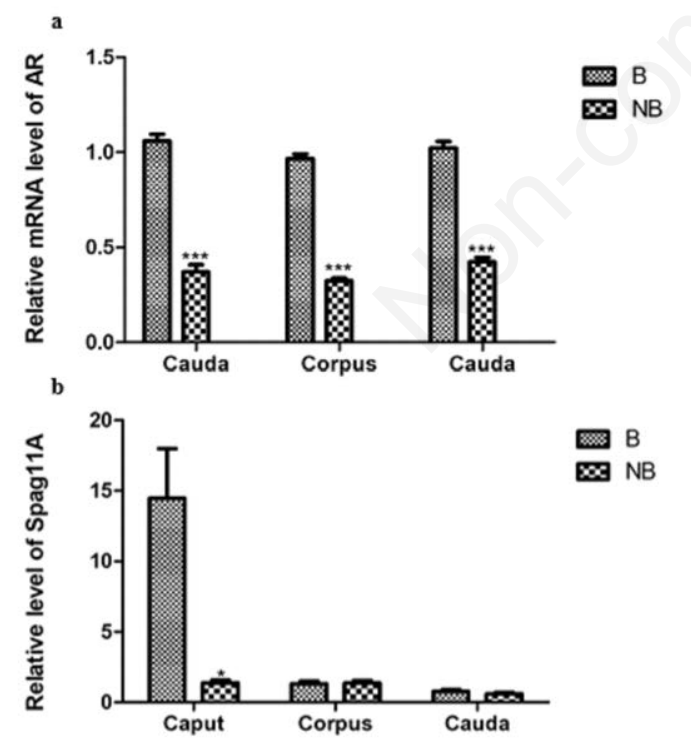

Figure 5. Expression levels of AR (a) and SPAG11A (b) mRNA during the annual reproductive cycle. Bars represent means \pm 5 independent experiments ( $n=5$ per season for Real-time PCR). Means within the columns marked with marks indicate significant difference. B: the breeding season; NB: the non-breeding season. Data are shown as the mean \pm SEM. ${ }^{*} \mathrm{P}<0.05 ;{ }^{* *} \mathrm{P}<0.01$; $* * * \mathbf{P}<\mathbf{0 . 0 0 1}$. zoa maturation and storage in the breeding season. Additionally, it was found that seasonal changes in the testicular function of the wild ground squirrels in previous studies had displayed a synchronous function with the epididymis. ${ }^{23}$ The previous correlated studies had also confirmed that the maximum active and regressive periods of the testis, along with the seasonal changes epididymal morphology, had stated an epididymal dependence on the levels of circulating testosterone during the breeding season. ${ }^{22}$ Taken together, the present results clarified that seasonal changes in the epididymis were a common phenomenon experienced by seasonal breeding mammals, providing deeper understanding of the morphological and histological changes in the epididymis of the wild ground squirrels.

\section{a \\ Concentration of FSH}
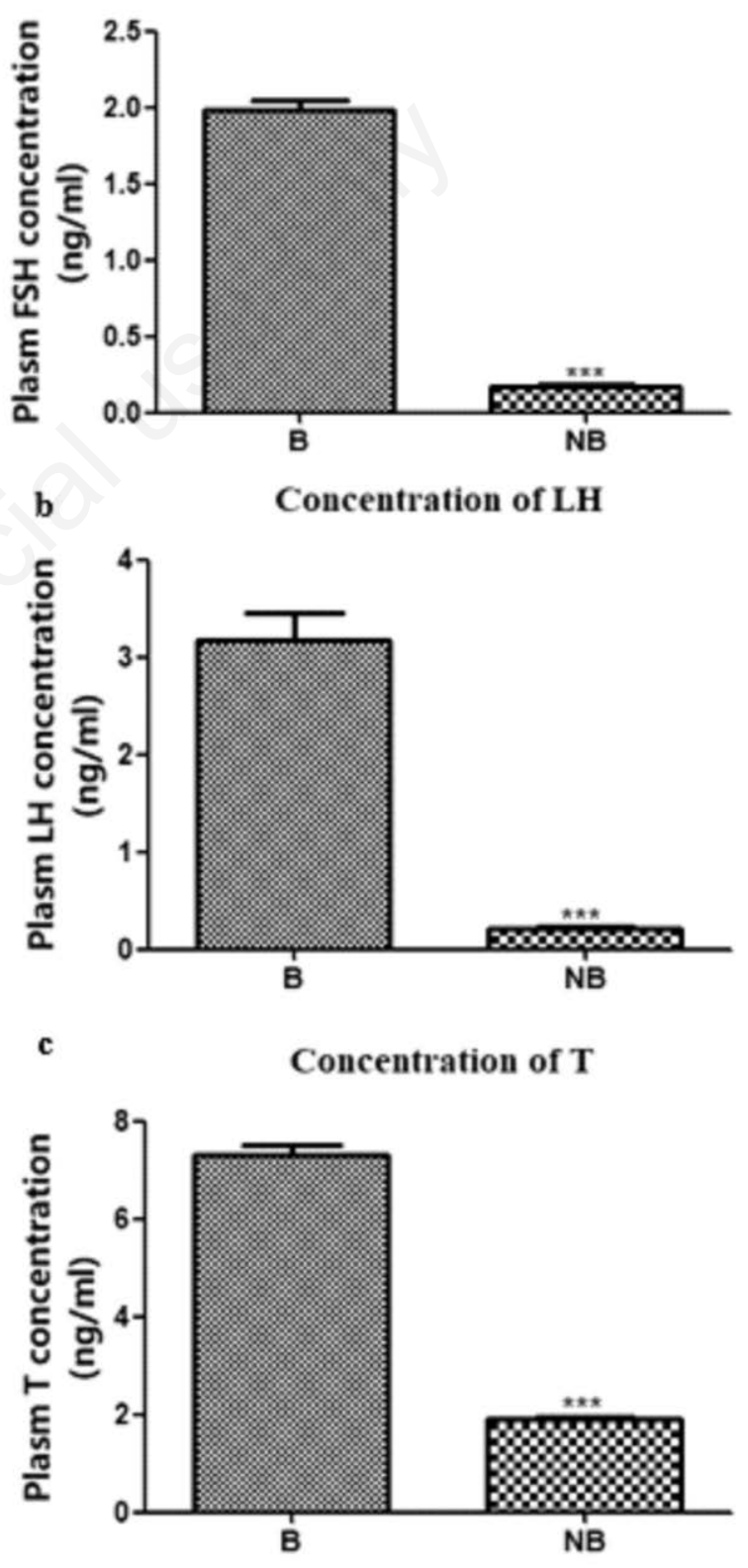

Figure 6. Seasonal change levels of FSH, LH and T (a-c) in the plasm of the wild ground squirrels. $B$, the breeding season; NB, the non-breeding season. Data are shown as the mean \pm SEM. $* * * \mathbf{P}<0.001$. 
The process of sperm maturation in the epididymis occurs by interaction between spermatozoa and proteins secreted by epididymal epithelium. ${ }^{33}$ The previous study confirmed that SPAG11A was a secretory protein present in the epididymal fluid and spermatozoa from the cauda epididymis and vas deferens, ${ }^{13}$ the protein secreted by principal cells mainly created the luminal microenvironment for sperm maturation and fertility. ${ }^{5}$ Our research found that the expression of SPAG11A mRNA displayed a region-specific pattern in epididymis during the breeding and non-breeding seasons, showing significantly higher SPAG11A mRNA level in the caput than those in the corpus and cauda. In the meantime, the present results revealed that the immunolabeling of SPAG11A and AR were mainly located in the principal cell in the caput epididymis. Consistently, the expression abundance of SPAG11A in epididymis of mouse and rat also showed region-specific model, ${ }^{14,34}$ and the secretion of SPAG11A in the lumen was proved to be from the principal cells as well. Furthermore, similar to Pujianto's results, ${ }^{13}$ we found that SPAG11A was present in the sperms in the lumen of epididymis, and the immunostaining of SPAG11A in the corpus and cauda epididymis was higher than these in the caput epididymis. These results implied that epithelium cells secreted SPAG11A into luminal fluid of the caput epididymis and bound to the sperm in the corpus and cauda epididymis. Taken together, the data predicated that SPAG11A might be involved in epididymal sperm maturation and fertilization.

Androgens are the primary modulators of epididymal structure, gene expression and function, and acknowledged as important regulators of epididymal $\beta$-defensins expression in multiple species. ${ }^{35}$ Identification of androgen-regulated $\beta$-defensins transcriptomes has important significances for our understanding the process of sperm maturation. ${ }^{17}$ Several studies reported that some kinds of $\beta$-defensins might be regulated by androgen in a range of animals, such as rats, ${ }^{36}$ monkeys, ${ }^{37}$ humans ${ }^{38}$ and mice. ${ }^{13}$ The epididymis from castrated animals displayed down-regulation of different SPAG11A transcripts, and that phenomenon could be reversed by testosterone addition in the castrated animals, ${ }^{13,39}$ suggesting a stimulated effect of androgen on the expression of SPAG11A. In this study, the expression of SPAG11A and AR were paralleled with T concentrations in the epididymis of wild ground squirrels during seasonal breeding cycle. Although, SPAG11A directly binding with AR targets has not been proved in the present study, it has been widely accepted that AR binding sites are associated with $\beta$-defensins. For example, SPAG11A was reported to be direct regulated by AR in mouse. ${ }^{17} \mathrm{Study}$ in human and mouse also showed that the identification of AR response elements in the 5'-flanking region of SPAG11A of different species has provided further proof of the potential androgen modulation of SPAG11A by using ChIP-PCR/qPCR assays. ${ }^{17}$ In our future studies, the related experiments are also needed to verify the regulation of androgen on the expression of SPAG11A in the epididymis of the wild ground squirrels. The current data provided evidence in support of the views that spermatozoa maturation might be related to epididymal SPAG11A expressions, and SPAG11A expressions was speculated to be under the regulation of androgen/AR regulation. ${ }^{17}$

In conclusion, the present study clearly demonstrated the localization and expression patterns of AR and SPAG11A in epididymis of the wild ground squirrels during the breeding and non-breeding seasons. These findings predicated that upregulation of circulating $\mathrm{T}$ concentration and AR mRNA levels during the breeding season have parallel with the expression of SPAG11A protein in the epididymis, and SPAG11A was interactive with androgen participated in creating a microenvironment for sperm maturation in the epididymal lumen. The present study provides new orientation into the mechanisms of androgen regulation on epididymal $\beta$-defensins in seasonal breeders, enabling a better understanding of the functions of $\beta$-defensins in sperm maturation and fertility.

\section{Acknowledgments}

This research work is supported by Fundamental Research Funds for the Central Universities (NO. 2018ZY31), Beijing Natural Science Foundation (8182039) and National Natural Science Foundation of China (31872320, 21806010).

\section{References}

1. Cosentino MJ, Cockett AT. Structure and function of the epididymis. Urol Res 1986;14:229-40.

2. Guo Y, Li JM, Xiang Y, Li YY, Huang J, Deng XZ, et al. Quantitative (stereological) study of the epididymis and seminal vesicle in the rat from young to old. Andrologia 2019;51:e13247.

3. Cornwall GA. New insights into epididymal biology and function. Hum Reprod Update 2009;15:213-27.

4. Sipila P, Bjorkgren I. Segment-specific regulation of epididymal gene expression. Reproduction 2016;152:R91-9.

5. Breton S, Ruan YC, Park YJ, Kim B. Regulation of epithelial function, differentiation, and remodeling in the epididymis. Asian J Androl 2016;18:3-9.

6. Browne JA, Yang R, Leir SH, Eggener SE, Harris A. Expression profiles of human epididymis epithelial cells reveal the functional diversity of caput, corpus and cauda regions. Mol Hum Reprod 2016;22:69-82.

7. Hermo L, Korah N, Gregory M, Liu LY, Cyr DG, D’Azzo A, et al. Structural alterations of epididymal epithelial cells in cathepsin A-deficient mice affect the blood-epididymal barrier and lead to altered sperm motility. J Androl 2007;28:784-97.

8. Charest NJ, Petrusz P, Ordronneau P, Joseph DR, Wilson EM, French FS. Developmental expression of an androgen-regulated epididymal protein. Endocrinology 1989;125:942-7.

9. Torres AM, Kuchel PW. The beta-defensin-fold family of polypeptides. Toxicon 2004;44:581-8.

10. Meade KG, O'Farrelly C. Beta-defensins: Farming the microbiome for homeostasis and health. Front Immunol 2018;9:3072.

11. Patil AA, Cai Y, Sang Y, Blecha F, Zhang G. Cross-species analysis of the mammalian beta-defensin gene family: presence of syntenic gene clusters and preferential expression in the male reproductive tract. Physiol Genomics 2005;23:5-17.

12. Dorin JR. Novel phenotype of mouse spermatozoa following deletion of nine beta-defensin genes. Asian J Andro. 2015; 17:716-9.

13. Pujianto DA, Loanda E, Sari P, Midoen YH, Soeharso P. Spermassociated antigen $11 \mathrm{~A}$ is expressed exclusively in the principal cells of the mouse caput epididymis in an androgen-dependent manner. Reprod Biol Endocrinol 2013;11:59.

14. Sangeeta K, Yenugu S. siRNA-mediated knockdown of spermassociated antigen 11a (Spag11a) mRNA in epididymal primary epithelial cells affects proliferation: a transcriptome analyses. Cell Tissue Res 2019;379:601-12.

15. Hall SH, Yenugu S, Radhakrishnan Y, Avellar MC, Petrusz P, French FS. Characterization and functions of beta defensins in the epididymis. Asian J Androl 2007;9:453-62.

16. Damyanova V, Dimitrova-Dikanarova D, Hadjidekova S, Savov A, Nesheva D, Rukova B, et al. [Genomic study in patients with idiopathic azoospermia and oligoasthenoteratozoospermia]. [Article in Bulgarian]. Akush Ginekol (Sofiia) 2013;52:27-34.

17. Hu SG, Zou M, Yao GX, Ma WB, Zhu QL, Li XQ, et al. Androgenic regulation of beta-defensins in the mouse epididymis. Reprod Biol Endocrinol 2014;12:76.

18. Biswas B, Yenugu S. Transcriptional regulation of the rat spermassociated antigen 11e (Spag 11e) gene during endotoxin chal- 
lenge. Mol Genet Genomics 2014;289:837-45.

19. Wang Y, Wang Z, Yu W, Sheng X, Zhang H, Han Y, et al. Seasonal expressions of androgen receptor, estrogen receptors and cytochrome P450 aromatase in the uteri of the wild Daurian ground squirrels (Spermophilus dauricus). Eur J Histochem 2018;62:2889.

20. Zhang F, Wang J, Jiao Y, Zhang L, Zhang H, Sheng X, et al. Seasonal changes of androgen receptor, estrogen receptors and aromatase expression in the medial preoptic area of the wild male ground squirrels (Citellus dauricus Brandt). Eur J Histochem 2016;60:2621.

21. Bao L, Li Q, Liu Y, Li B, Sheng X, Han Y, et al. Immunolocalization of NGF and its receptors in ovarian surface epithelium of the wild ground squirrel during the breeding and nonbreeding seasons. Eur J Histochem 2014;58:2363.

22. Wang J, Wang Y, Zhu M, Zhang F, Sheng X, Zhang H, et al. Seasonal expression of luteinizing hormone receptor and follicle stimulating hormone receptor in testes of the wild ground squirrels (Citellus dauricus Brandt). Acta Histochem 2017;119:727-32.

23. Li Q, Zhang F, Zhang S, Sheng X, Han X, Weng Q, et al. Seasonal expression of androgen receptor, aromatase, and estrogen receptor alpha and beta in the testis of the wild ground squirrel (Citellus dauricus Brandt). Eur J Histochem 2015;59:2456.

24. Zhang M, Sheng X, Zhang H, Wang Q, Xu M, Weng Q, et al. Seasonal changes in morphology and immunoreactivity of PDGF-A and its receptor PDGFR-alpha in the epididymis of wild ground squirrels (Citellus dauricus Brandt). J Reprod Dev 2012;58:353-9.

25. Guh YJ, Tamai TK, Yoshimura T. The underlying mechanisms of vertebrate seasonal reproduction. Proc Jpn Acad Ser B Phys Biol Sci 2019;95:343-57.

26. Zhang M, Sheng X, Sun R, Li Q, Zhang H, Zhou J, et al. Seasonal changes in immunoreactivity of inhibin/activin subunits in the epididymis of wild ground squirrels (Citellus dauricus Brandt). J Reprod Dev 2013;59:302-7.

27. Rosati L, Prisco M, Di Lorenzo M, De Falco M, Andreuccetti P. Immunolocalization of aromatase P450 in the epididymis of Podarcis sicula and Rattus rattus. Eur J Histochem 2020;64:3080.

28. Campolina-Silva GH, Hess RA, Oliveira CA. Seasonal variation of cell proliferation and apoptosis in the efferent ductules and epi- didymis of the Neotropical bat Artibeus lituratus (Chiroptera, Phyllostomidae). Gen Comp Endocrinol 2019;273:3-10.

29. Ibrahim ZH, Joshi D, Singh SK. Seasonal immunohistochemical reactivity of S-100 and alpha-smooth muscle actin proteins in the epididymis of dromedary camel, Camelus dromedarius. Andrologia 2017;49:e12667.

30. Menad R, Fernini M, Smai S, Bonnet X, Gernigon-Spychalowicz T, Moudilou E, et al. GPER1 in sand rat epididymis: Effects of seasonal variations, castration and efferent ducts ligation. Anim Reprod Sci 2017;183:9-20.

31. Aguilera-Merlo C, Munoz E, Dominguez S, Scardapane L, Piezzi R. Epididymis of viscacha (Lagostomus maximus maximus): morphological changes during the annual reproductive cycle. Anat Rec A Discov Mol Cell Evol Biol 2005;282:83-92.

32. Calvo A, Bustos-Obregon E, Pastor LM. Morphological and histochemical changes in the epididymis of hamsters (Mesocricetus auratus) subjected to short photoperiod. J Anat 1997;191:77-88.

33. Gervasi MG, Visconti PE. Molecular changes and signaling events occurring in spermatozoa during epididymal maturation. Andrology 2017;5:204-18.

34. Dorin JR, Barratt CL. Importance of beta-defensins in sperm function. Mol Hum Reprod 2014;20:821-6.

35. Ribeiro CM, Silva EJ, Hinton BT, Avellar MC. beta-defensins and the epididymis: contrasting influences of prenatal, postnatal, and adult scenarios. Asian J Androl 2016;18:323-8.

36. Hu S, Yao G, Guan X, Ni Z, Ma W, Wilson EM, et al. Research resource: Genome-wide mapping of in vivo androgen receptor binding sites in mouse epididymis. Mol Endocrinol 2010; 24:2392-405.

37. Jalkanen J, Huhtaniemi I, Poutanen M. Discovery and characterization of new epididymis-specific beta-defensins in mice. Biochim Biophys Acta 2005;1730:22-30.

38. Oh J, Lee J, Woo JM, Choi E, Park I, Han C, et al. Systematic identification and integrative analysis of novel genes expressed specifically or predominantly in mouse epididymis. BMC Genomics 2006;7:314.

39. Frohlich O, Po C, Young LG. Organization of the human gene encoding the epididymis-specific EP2 protein variants and its relationship to defensin genes. Biol Reprod 2001;64:1072-9.

Received for publication: 16 January 2020. Accepted for publication: 2 April 2020.

This work is licensed under a Creative Commons Attribution-NonCommercial 4.0 International License (CC BY-NC 4.0).

CCopyright: the Author(s), 2020

Licensee PAGEPress, Italy

European Journal of Histochemistry 2020; 64:3111

doi:10.4081/ejh.2020.3111 